\title{
DIAL Tropospheric Ozone Measurement Using a Nd:YAG Laser and the Raman Shifting Technique
}

\author{
G. ANCellet, A. Papayannis, J. Pelon and G. MÉgie \\ Service d'Aéronomie du CNRS, Verrières, le Buisson, France
}

(Manuscript received 3 June 1988, in final form 29 March 1989)

\begin{abstract}
The Differential Absorption Lidar (DIAL) offers a way to perform ozone measurements in the troposphere with the spatial and temporal resolutions needed for both short and long term studies. Only a few DIAL systems have been used up to now for this purpose, relying mainly on tunable laser sources. In this paper, a new system using a Nd:YAG laser source and Raman shifting techniques to generate several wavelengths in the ultraviolet and the visible spectral range is proposed for use in a regional ozone network and in a small or medium size aircraft. This system has been operated in a ground-based station in southern France for nighttime ozone measurements in the free troposphere. A comparison with balloon borne Brewer-Mast ozonesonde data is presented and measurement accuracy of these two instruments is discussed.
\end{abstract}

\section{Introduction}

The overall budget of tropospheric ozone remains uncertain (Fishman 1985) and a net photochemical production of ozone of about $2 \times 10^{11} \mathrm{~mol} \mathrm{~cm}{ }^{-2} \mathrm{~s}^{-1}$ has been presently proposed to balance this budget in the troposphere of the Northern Hemisphere (Crutzen 1988). To obtain a better estimation of the processes acting on the ozone budget (i.e., dynamical exchanges through the transition zones and photochemical production during pollution episodes), it is necessary to constitute an ozone database at different temporal scales ( $2 \mathrm{~min}-1$ day) and with a spatial resolution ranging from 0.3 to $1 \mathrm{~km}$. For example, on short time scales, tropospheric ozone can be considered as a tracer of transient dynamical motions, so that one can study the small scale processes mainly responsible for ozone transfers through the transition zones in the troposphere (Vernin and Pelon 1986). The ozone database required for tropospheric applications should also include long term records to quantify the varying trends of ozone concentrations at various levels in the troposphere (Logan 1985).

Ultraviolet differential absorption lidar (DIAL) systems provide the necessary resolutions and measurement continuity. They have been operated for both stratospheric and tropospheric observations (Pelon and Mégie 1982a, 1982b; Browell et al. 1987), but only during field campaigns owing mainly to the complexity

Corresponding author address: Dr. G. Ancellet, Service d'Aeronomie, Centre National de la Recherche Scientifique, BP No. 3,91371 Verrières le Buisson Cedex, France. of the laser source operation (tunable dye laser). Since tropospheric ozone lidars are developed for operations in a small aircraft or routine measurements from a ground based station, the instrument will have to be as simple and as automatic as possible.

The purpose of this paper is to describe a new lidar system using a Nd:YAG laser and Raman shifting techniques to generate up to four wavelengths in the near UV and visible spectral range. The potential of Raman shifting techniques for tropospheric ozone measurements has been demonstrated in the case of a $\mathrm{KrF}$ excimer laser as a pumping source (Uchino et al. 1983). A system using a Nd:YAG laser offers a way to generate one wavelength in the visible $(0.35 \mu \mathrm{m}$ or $0.53 \mu \mathrm{m}$ ) for aerosol backscatter measurements, which will provide additional information for studies of atmospheric motions and for correction of the aerosol interferences in the DIAL technique (Browell et al. 1985). The current development of solid state laser technology also makes possible the integration of such a system in a small or medium size aircraft. The lidar subsystems are presented in section 2 and the first results obtained with this new laser source are discussed in section 4 in order to show the potential of the Nd: YAG transmitter compared to previous systems. In this paper, the data analysis is restricted to nighttime measurements in the free troposphere (i.e., measurements similar to those obtained so far with a groundbased lidar). An example of ozone profiles recorded using a grating spectrometer as part of the receiving module is also presented and finally, the evolution of the system design toward daytime measurement is discussed. 


\section{Experimental system}

Considering the future integration of the ozone lidar in an observation network or in an aircraft, a system has been designed to perform tropospheric ozone measurements with the following performances:

- altitude range: $0.1-15 \mathrm{~km}$

- vertical resolution: $0.3-1 \mathrm{~km}$

- integration time: $1-15 \mathrm{~min}$

- accuracy: better than $10 \%$

The accuracy on the concentration refers to the standard deviation of the concentration estimation and not to the bias which should be of the order of $1 \%$ to monitor long term ozone trends (Prinn 1988). The characteristics of the lidar system are summarized in Table 1 and a block diagram of the various subsystems is presented in Fig. 1. In this section a more complete description of each subsystem is provided.

\section{a. Transmitter}

The main part of the transmitter is a Nd:YAG laser (Quantel model 481) emitting $1.2 \mathrm{~J}$ per pulse at 1.06 $\mu \mathrm{m}$ with a repetition rate of $10 \mathrm{~Hz}$. Two KDP crystals are mounted in a serial arrangement to generate the second and fourth harmonic at 532 and $266 \mathrm{~nm}$, respectively, with an $8 \%$ total conversion efficiency, corresponding to a $90 \mathrm{~mJ}$ available output energy, at $266 \mathrm{~nm}$.

Although DIAL applications do not require a constant laser energy, it is advantageous to keep the energy close to its maximum in order to avoid the use of an electronic gain normalization of the lidar signal detec-

TABLE 1. Lidar system characteristics.

\begin{tabular}{|c|c|c|}
\hline \multicolumn{3}{|l|}{ Transmitter } \\
\hline $\begin{array}{l}\text { Wavelength } \\
\text { Output energy per } \\
\text { pulse }\end{array}$ & $\begin{array}{l}289 \mathrm{~nm} \\
8.5-10 \mathrm{~mJ}\end{array}$ & $\begin{array}{l}299 \mathrm{~nm} \\
6.5-8 \mathrm{~mJ}\end{array}$ \\
\hline $\begin{array}{l}\text { Pulse duration } \\
\text { Beam divergence } \\
\text { Pulse repetition rate }\end{array}$ & $\begin{array}{l}15 \mathrm{n} \\
<7.010^{-4} \mathrm{rad} \\
10 \mathrm{~Hz}\end{array}$ & $\begin{array}{l}15 \mathrm{n} \\
<7.010^{-4} \mathrm{rad} \\
10 \mathrm{~Hz}\end{array}$ \\
\hline \multicolumn{3}{|l|}{ Receiver } \\
\hline $\begin{array}{l}\text { Telescope diameter } \\
\text { Field of view } \\
\text { Receiver bandwidth } \\
\quad \text { (FWHM) } \\
\text { Total optical efficiency }\end{array}$ & $\begin{array}{l}80 \mathrm{~cm}(f=30 \\
10^{-3} \mathrm{rad} \\
3 \mathrm{~nm}^{*} \\
70 \mathrm{~nm}^{* *} \\
25 \%^{*} \\
60 \%^{* *}\end{array}$ & \\
\hline Photomultiplier & \multicolumn{2}{|c|}{$\begin{array}{l}\text { Bialkali photocathode } \\
20 \% \text { quantum efficiency }\end{array}$} \\
\hline $\begin{array}{l}\text { Detection mode } \\
\text { waveform recorder } \\
\text { photon counter }\end{array}$ & \multicolumn{2}{|c|}{$\begin{array}{l}10 \mathrm{MHz}-12 \text { bits } \\
2 \mu \mathrm{s}-20 \mathrm{MHz}\end{array}$} \\
\hline
\end{tabular}

* grating spectrometer.

** interference filter. tor output. A special electronic feedback loop was built, to compensate for energy variations of the laser output at $266 \mathrm{~nm}$ due to the angular detuning of the frequency doubling KDP crystals as a consequence of their temperature variations. The operation principle is based on the continuous detection, by two photodiodes, of the two residual laser beams not converted through the frequency doubling process ( $a: 532 \mathrm{~nm}$ for the fourth harmonic generator and at $1.064 \mu \mathrm{m}$ for the second harmonic). The photodiode signals are kept close to their minimum values through dithering of the tuning angle and peak value detection of the photodiode output. Using a stepping motor to tune the crystal, we obtained a $\pm 10 \%$ stability of the output energy at $266 \mathrm{~nm}$.

The laser beam at $266 \mathrm{~nm}$ is split into two parts to optically pump the hydrogen $\left(\mathrm{H}_{2}\right)$ and deuterium $\left(\mathrm{D}_{2}\right)$ Raman cells with $40 \mathrm{~mJ}$ and $50 \mathrm{~mJ}$ of pumping energy, respectively. Two $1-\mathrm{m}$ fused silica plane convex lenses focus the two laser beams close to the center of the 60 $\mathrm{cm}$ long high pressure stainless steel cells. The expected energy conversion efficiency for generation of the first Stokes line $S_{1}$ by nonresonant stimulated Raman scattering is reported in Figs. 2a, b. The output energy on the first Stokes line was near its optimum value for a 50 bar gas pressure in the cell. No antireflection coating was added onto the Raman cell windows and the lenses, to prevent burning the optical elements with the high power density of the pumping frequency. Consequently, a $10 \mathrm{~mJ}$ average output energy at $289 \mathrm{~nm}$ and $8 \mathrm{~mJ}$ at $299 \mathrm{~nm}$ were obtained corresponding to a $22 \%$ $25 \%$ net energy conversion efficiency for our system. The beam divergence after collimation by a 1-m lens was measured to be $0.7 \mathrm{mrad}$, and the laser beam is therefore transmitted in the atmosphere without an additional beam expander.

\section{b. Optical receiver and data acquisition system}

The backscattered UV signal is collected by an 80 $\mathrm{cm}$ diameter Cassegrain telescope in a vertical position with an equivalent focal length of $30 \mathrm{~m}$. The distance between the emitting point and the telescope axis is about $1 \mathrm{~m}$, and the telescope field of view can be adjusted from its minimum value compatible with the laser divergence $(0.7 \mathrm{mrad})$ up to $1.2 \mathrm{mrad}$. The field of view of the transmitter and the receiver then begin to overlap fully above $2 \mathrm{~km}$.

Because of the short wavelength separation between the simultaneously emitted wavelengths (289-299 $\mathrm{nm}$ ), no dichroic beamsplitter can be used to achieve an efficient DIAL signal separation with high transmission efficiencies $(>30 \%)$. Up to now, a UV broadband filter with a $70 \mathrm{~nm}$ bandwidth was used to separate the alternately emitted wavelengths from the nighttime background sky light. For daytime measurements, the new detection system includes a $3 \mathrm{~nm}$ bandpass Czerny-Turner spectrometer (focal length $=600 \mathrm{~cm}$ ) 


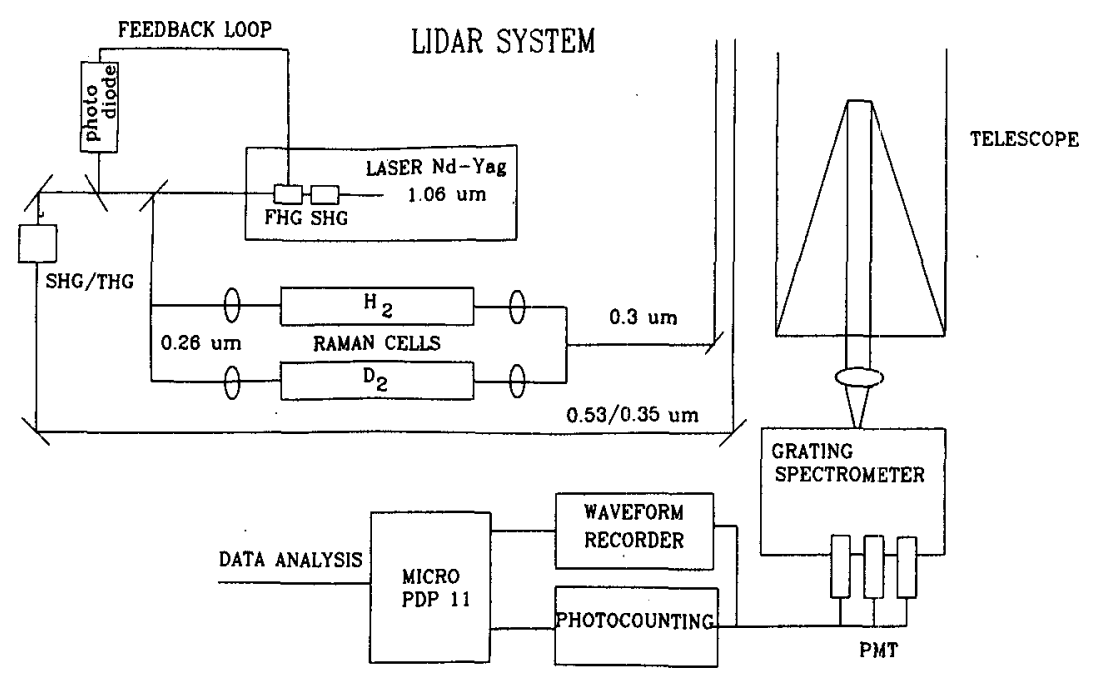

FIG. 1. The UV ozone lidar system.

instead of the broadband filter. The image of the telescope aperture is formed onto the diffraction grating surface, while the exit focal plane coincides with the photomultiplier tube (PMT) photocathodes. The $3 \mathrm{~nm}$ spectral resolution of the detection system is principally determined by the width of the input aperture adapted to the value of the telescope field of view. The $600 \mathrm{~mm}$ focal length is long enough for optical interferences from one channel to the other to be negligible $\left(<10^{-3}\right)$. The optical detection system can be used to receive simultaneously several signals (up to 4-5 different wavelengths) with an optical transmission efficiency of the order of $30 \%$. Another way to achieve low noise measurements during daytime conditions could be using a Fabry Perot etalon or a Fizeau interferometer, both of which have theoretically higher transmissions; however, a minimum interval spectral range of $30 \mathrm{~nm}$ is needed to avoid the overlap between the various interference orders corresponding to the emitted wavelengths $(266,289,299 \mathrm{~nm})$. The etalon width would then be of the order of $3 \mu \mathrm{m}$ and the etalon becomes similar to an interference filter, the transmission of which does not exceed $10 \%-15 \%$ for a $3 \mathrm{~nm}$ bandwidth.

\section{c. Data acquisition system}

Because of the large variation of the backscattered lidar signal dynamical range between 0 and $15 \mathrm{~km}$ altitude, two signal acquisition modes are employed.

For the lower altitude range up to $10 \mathrm{~km}$ the signal delivered by the photomultiplier tube is recorded by a 12-bit transient analyzer with a $10 \mathrm{MHz}$ sampling frequency (maximum sampling resolution of $15 \mathrm{~m}$ ), and 2048 storing channels. For the higher altitude levels (above $10 \mathrm{~km}$ ) where the signal is low enough, a 256channel photon counter is used with a $1 \mathrm{MHz}$ sampling frequency (maximum altitude resolution of $150 \mathrm{~m}$ ).
The data provided by the two acquisition modes are then sent to a micro-PDP 11 computer for further analysis and storage. The computer is used to control the full sequence of a DIAL measurement. The exper-
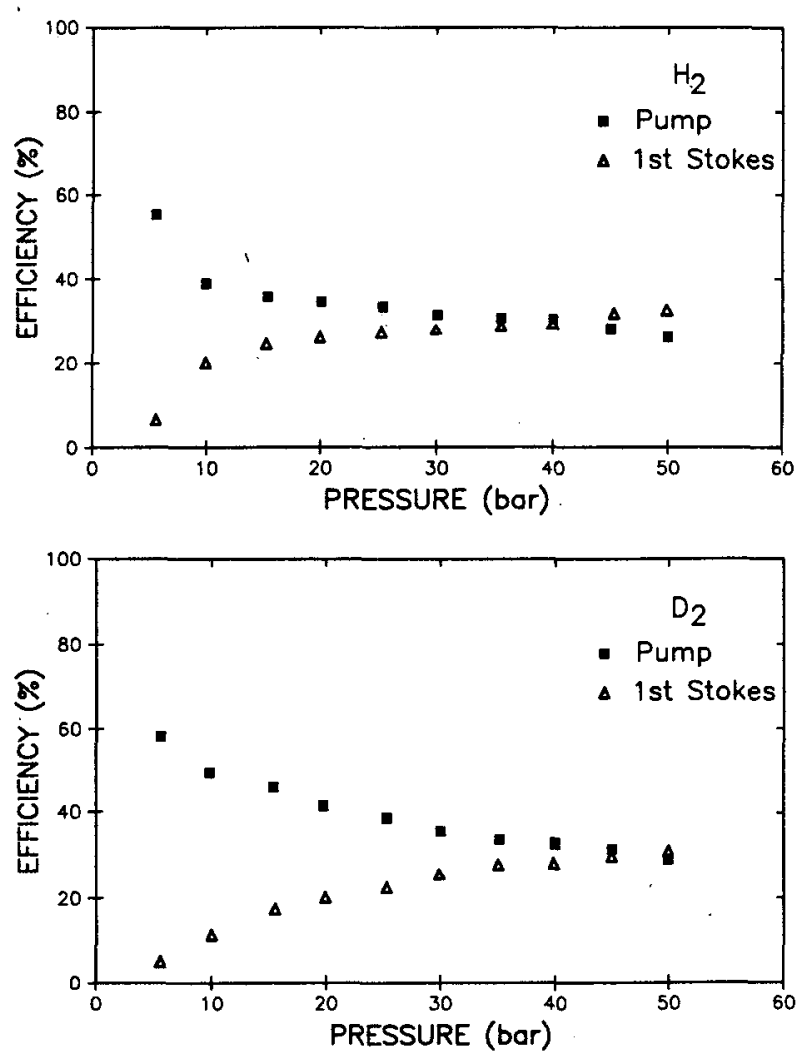

FIG. 2. Energy efficiency of the Stimulated Raman Generation of the first Stokes versus $H_{2}$ pressure (a) and $D_{2}$ pressure (b) for a pumping energy $E_{\text {input }}=55 \mathrm{~mJ}$. 
iment parameters (acquisition time, altitude resolution, values of the various laser wavelengths, number of shots, etc.) are typed in to start the sequence of laser firings automatically.

\section{Error analysis}

In this paper, the differential absorption technique will not be detailed since it has been extensively studied by various authors after it was first proposed by Schotland (1964). Its application to stratospheric and tropospheric ozone measurements was demonstrated both for ground based (Pelon and Mégie 1982a) and airborne (Browell et al. 1987) lidar. In the previous papers, however, emphasis was placed on wavelength optimization since tunable laser sources were first proposed to generate the emission lines in the UV. We will therefore perform the error analysis of the system described in section 1 for the emission lines (289 nm, $299 \mathrm{~nm}$ ) arising from the choice of the laser source although it does not necessarily correspond to the optimum wavelength selection as has been previously discussed for tunable laser sources (Pelon and Mégie 1982b).

The accuracy on the ozone concentration $\epsilon$ depends on many parameters and can be written as the sum of two terms:

- The first, $\epsilon_{1}$, is a statistical error associated with the signal and sky background noise fluctuations and can be calculated using the system parameters (emitted energy, telescope size, integration time) and the ozone absorption coefficients.

- The second, $\epsilon_{2}$, is a systematic error due to the wavelength dependence of the scattering and absorbing properties of the atmosphere in each volume element contributing to the return signal. This error is corrected to a first approximation by using an atmospheric model for the molecular density (U.S. Standard Atmosphere 1976).

Using the expression of these errors (as given, for example, by Mégie et al. 1985), the error analysis has been performed for the wavelength pair (289-299 nm) with an emphasis on the measurements in the free troposphere $(2-15 \mathrm{~km})$. For this altitude range, $\epsilon_{2}$ is generally very small compared to $\epsilon_{1}$, provided that the differential extinction due to Rayleigh scattering has been corrected. This can be done by using a pressure and temperature model to derive the atmospheric density. After this correction, the residual error $\epsilon_{2}$ on the ozone concentration does not exceed $4.10^{9} \mathrm{~mol} \mathrm{~cm}^{-3}$ $(0.4 \mathrm{ppb}$ mixing ratio) in the free troposphere considering a temperature variability of $\pm 5^{\circ} \mathrm{C}$ at midlatitude. The error $\epsilon_{1}$ is presented in Fig. 3 for nighttime measurements and three vertical resolutions $(300 \mathrm{~m}, 500$ $\mathrm{m}, 1000 \mathrm{~m}$ ). The lidar parameters are those presented in Table 1 and 1000 shots are averaged for each wavelength. When the integration time is increased up to one hour, the spatial resolution can be improved to

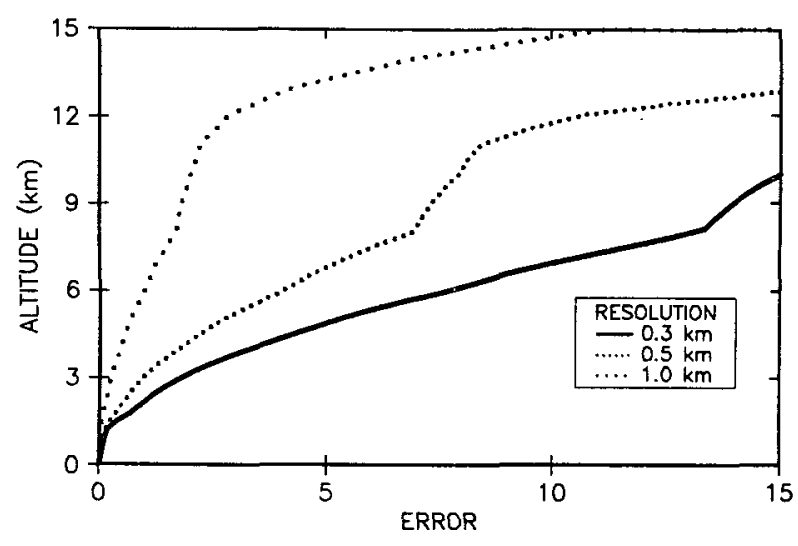

FIG. 3. Altitude dependence of the nighttime statistical error $\epsilon_{1}$ (1000 laser shots), for three different vertical resolutions.

$300 \mathrm{~m}$ at altitudes higher than $6 \mathrm{~km}$. For trend analysis, the $1-\mathrm{h}$ profile with a $1 \mathrm{~km}$ spatial resolution would lead to a $2 \%$ statistical error up to $15 \mathrm{~km}$.

The $10 \%$ statistical error indicated in Fig. 3 at 15 $\mathrm{km}$ represents the variance of the ozone measurements. This $10 \%$ value remains the same when one takes the average of the calculated ozone concentrations rather than the signal average, provided that the signal-tonoise ratio is greater than 10 (Theopold and Bösenberg 1988). Averaging of the concentrations might be relevant in case of ozone or aerosol backscatter variations on time scales shorter than a few minutes.

For trend analysis, the other important parameter is the bias on the mean concentration obtained with an averaging over a very large number of shots. To estimate this bias, we simulated our ozone processing technique using a known ozone profile to compute the lidar signals at both wavelengths. The profile derived from the DIAL algorithm is compared to the initial one to obtain the bias. A noise is added to the mean signal by generating random numbers with a variance proportional to the square root of the signal (shot noise limit). The results in Fig. 4 indicate a bias smaller than $1 \%$ up to $19 \mathrm{~km}$, showing clearly that trends on the ozone measurements can be evaluated up to $15 \mathrm{~km}$ during nighttime. For example, referring to Frederick (1983), a fractional error of $0.4 \%$ /yr would require a 5 -year measurement program, if two 1 -h profiles are performed per week with a $3 \%$ instrumental precision.

It should be pointed out that we assume, in this error analysis, a data acquisition system that can process a backscattered signal with a dynamical range larger than $10^{6}$. Therefore the discrepancies that might occur between the measured errors and the calculated errors often arise from the difficulty to cover such a dynamical range.

\section{Results}

The new lidar system described in section 2 has been used at the Observatoire de Haute Provence $\left(44^{\circ} \mathrm{N}\right.$, 


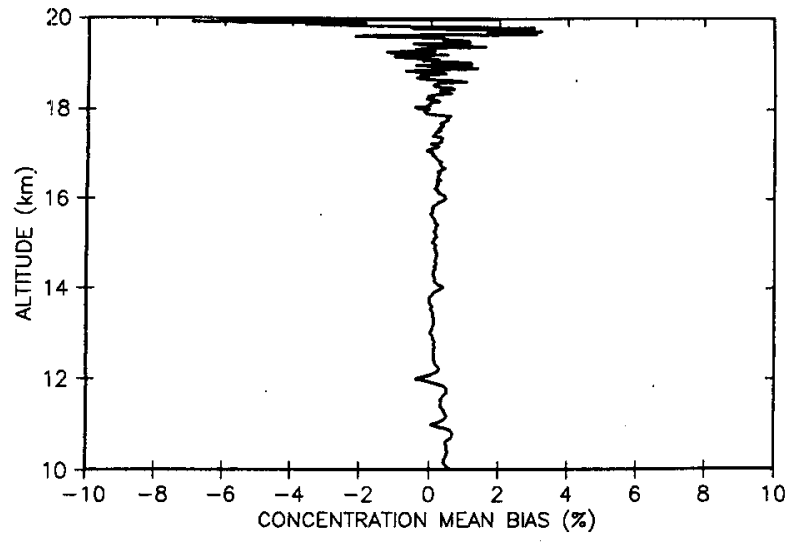

FIG. 4. Altitude dependence of the nighttime ozone concentration bias ( 1000 laser shots), for a variable resolution ( $\Delta z=0.9 \mathrm{~km}$ à 11 $\mathrm{km}, 1.2 \mathrm{~km}$ à $20 \mathrm{~km}$ ).

$5^{\circ} \mathrm{W}, 700 \mathrm{~m}$ ASL) for nighttime measurements of the ozone profile from 3 to $15 \mathrm{~km}$. The broadband filter with a $70 \mathrm{~nm}$ bandwidth and a $70 \%$ transmission efficiency was used instead of the spectrometer in this first version to test the potential of the new laser transmitter in the first place. The two wavelengths were then time separated by switching the wavelengths on a shotto-shot basis.

\section{a. Data analysis}

The present capability of this new lidar system can be shown by plotting on the same graph vertical ozone profiles recorded sequentially on the same night. Figure 5 shows an example of three consecutive profiles resulting from an acquisition of 1000 shots. The average signal for each wavelength was sampled and a running low pass digital filter was applied to the total record. The smoothing method was a running least-square fit of the dataset to a second order polynomial, which often represents a good fit for the vertically decreasing atmospheric scale height. To obtain the signal derivative, the digital filter must correspond to a linear transfer function in the frequency bandwidth of the low-pass filter (i.e., a frequency ranging from zero to one-fifth of the Nyquist frequency). A Taylor development of the transfer function truncated to second order has been considered and the five corresponding weights of the filter are $(1 / 12,-2 / 3,0,2 / 3,-1 / 12)$.

The spatial resolution of the measurement is related to the number $2 n+1$ of data points fitted to the second order polynomial (for our low-pass filter, a fitting on 40 points recorded with the waveform recorder leads to a $1 \mathrm{~km}$ spatial resolution ). In the data processing, fitting can be increased with range so that the spatial resolution is kept close to $200 \mathrm{~m}$ at short range $(3 \mathrm{~km})$ and is increased up to $1 \mathrm{~km}$ at higher altitudes (15 $\mathrm{km})$, where the signal to noise ratio is large enough (Godin 1987).
The error bars were calculated for both detection modes (waveform recorder and photocounter) assuming that the signal detection process follows a Poisson distribution. The experimental error does not exceed $20 \%$ in the altitude range $4-12 \mathrm{~km}$. The differences between the three ozone profiles are well within the error bars of each profile for these successive profiles separated in time by less than $5 \mathrm{~min}$. The error values at $12 \mathrm{~km}$ are slightly higher than expected after the previous error analysis, because typical ozone values less than $6 \times 10^{11} \mathrm{~mol} \mathrm{~cm}^{-3}$ up to $10 \mathrm{~km}$ were used to perform the calculation in section 3 (U.S. Standard Atmosphere 1976). High ozone concentration in the troposphere $\left(>10^{12} \mathrm{~mol} \mathrm{~cm}{ }^{-3}\right)$ reduces the backscattered signal from the lower stratosphere by a factor larger than 2.

No data points are given below $4 \mathrm{~km}$ ASL because the data acquisition system is not presently able to handle the very large dynamical range of the lidar signal between 0.1 and $15 \mathrm{~km}$. The implementation in the data acquisition system of a two-stage gain amplifier will reduce the dynamical range and the profiles should be extended down to $2 \mathrm{~km}$ ASL. A further step to get ozone measurements in the planetary boundary layer (PBL) would require using a coaxial arrangement for the emitting/receiving optics to reduce the effect of a possible difference between the optical overlap functions corresponding to each wavelength.

\section{b. Comparison lidar/Brewer-Mast sonde}

At the Observatoire de Haute Provence (OHP) geophysical station and in addition to the ozone lidar, a Dobson spectrophotometer supplies daily total ozone content and ozone profiles (Umkehr method) and Brewer-Mast ozonesondes are launched regularly giving ozone vertical profiles from the ground up to 30 $32 \mathrm{~km}$. For the evening of 25 March 1988, a comparison was made between lidar vertical ozone profiles and a Brewer-Mast sounding. The lidar results are

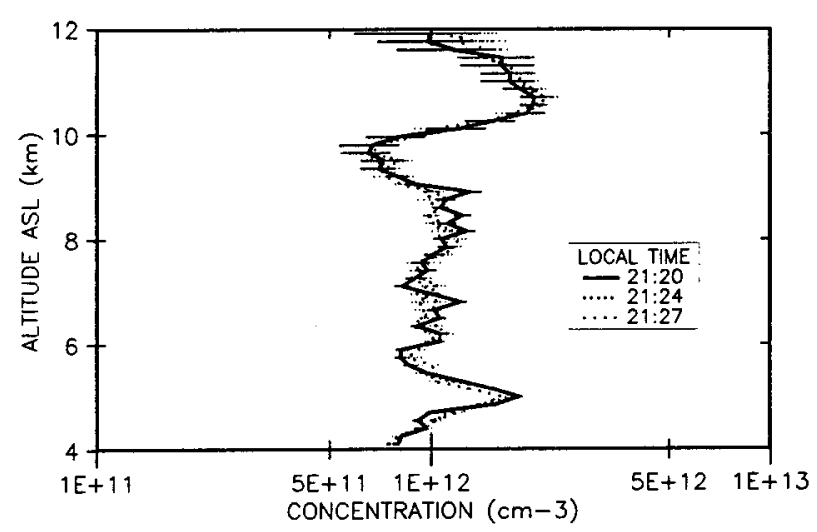

FIG. 5. Ozone concentration vertical profiles measured at night by lidar at the OHP (broadband filter). 
given in ozone number density $\left(\mathrm{mol} \mathrm{cm} \mathrm{cm}^{-3}\right)$ as a function of geometric altitude $(\mathrm{km})$. Since the Brewer-Mast data also include total pressure and temperature, both given by the meteorological sonde, ozone partial pressure can be converted to number density using the perfect gas law. The altitude $Z_{i}$ is calculated at each pressure level $p_{i}$ using the Laplace equation

$$
Z_{i+1}=Z_{i}+67.445 T_{i} \log \left(p_{i} / p_{i+1}\right)
$$

where $T_{i}$ is the virtual temperature of the atmospheric layer located between the pression levels $p_{i}$ and $p_{i+1}$.

The temporal evolution of lidar observations made at the Observatoire is plotted for a $1 \mathrm{~h}$ period around the balloon launch time ( 2315 local time) and for altitudes ranging from 4 to $10 \mathrm{~km}$ (Fig. 6). During this time interval, thin cloud layers between 9.5 and $11 \mathrm{~km}$ made the retrieval of ozone data at these altitudes difficult, without a correction of the aerosol backscatter interferences in the clouds. The effect of the cloud layers passing over can be identified on Fig. 6 as sharp transitions from high to low ozone concentrations. Above the cloud layers, however, the backscattered signal was still large enough to derive ozone concentrations. The Brewer-Mast ozonesonde response time is larger than $30 \mathrm{sec}$ corresponding to a $90-120 \mathrm{~m}$ vertical resolution for a 3-4 $\mathrm{m} \mathrm{s}^{-1}$ ascending balloon velocity. This value is therefore better than the lidar resolution for altitudes higher than $10 \mathrm{~km}$ and a binomial filter was applied to the balloon data at these altitudes. A $3 \mathrm{~min}$ average ozone profile taken at 2303 is compared to the BrewerMast profile on Fig. 7 up to a $14 \mathrm{~km}$ altitude. The general agreement between both profiles is good, but several additional comments should be made about this comparison:
- lower ozone concentrations measured by BrewerMast ozonesonde during the beginning of the ascent are often due to a contamination of the air intake system in the lower troposphere (De Muer and Malcorps 1984). Using a zero level, which is $10 \mathrm{ppb}$ lower, we get a new ozone profile which fits the lidar profile above $10 \mathrm{~km}$ quite well, but with a poorer agreement where the Brewer-Mast concentrations are the lowest.

- a correction factor of 1.25 was applied to the sonde data since the $268 \mathrm{DU}$ total content calculated from the zonde ozone profile was normalized to the Dobson spectrophotometer value (335 DU). This value is somewhat higher than the average correction factor, which is usually close to 1.1 at the OHP.

- ozone data produced by both instruments do not necessarily represent the same air masses. This is quite important considering that the ozone variability could reach $30 \%$ on a time scale typical of that necessary for a balloon to reach the level of $15 \mathrm{~km}$ (Fig. 6).

This last remark led us to estimate the balloon trajectory on a surface parallel to the horizontal wind vector. The trajectory was calculated using the vertical profile of the horizontal component of the wind and the balloon ascent velocity since no radar tracking is available at the Observatoire. The wind profile was deduced from meteorological data obtained at noon on 25 and 26 March, although the balloon motion and the air mass trajectories are never purely bidimensional, the ozone distribution on this surface is somewhat similar to the temporal evolution represented on Fig. 6 and we can plot the balloon trajectory on this figure. In this particular example, the wind velocity exceeded $35 \mathrm{~m} \mathrm{~s}^{-1}$ at $500 \mathrm{mb}$ and nevertheless the gondola stayed more or less in the air masses that were over the Ob-

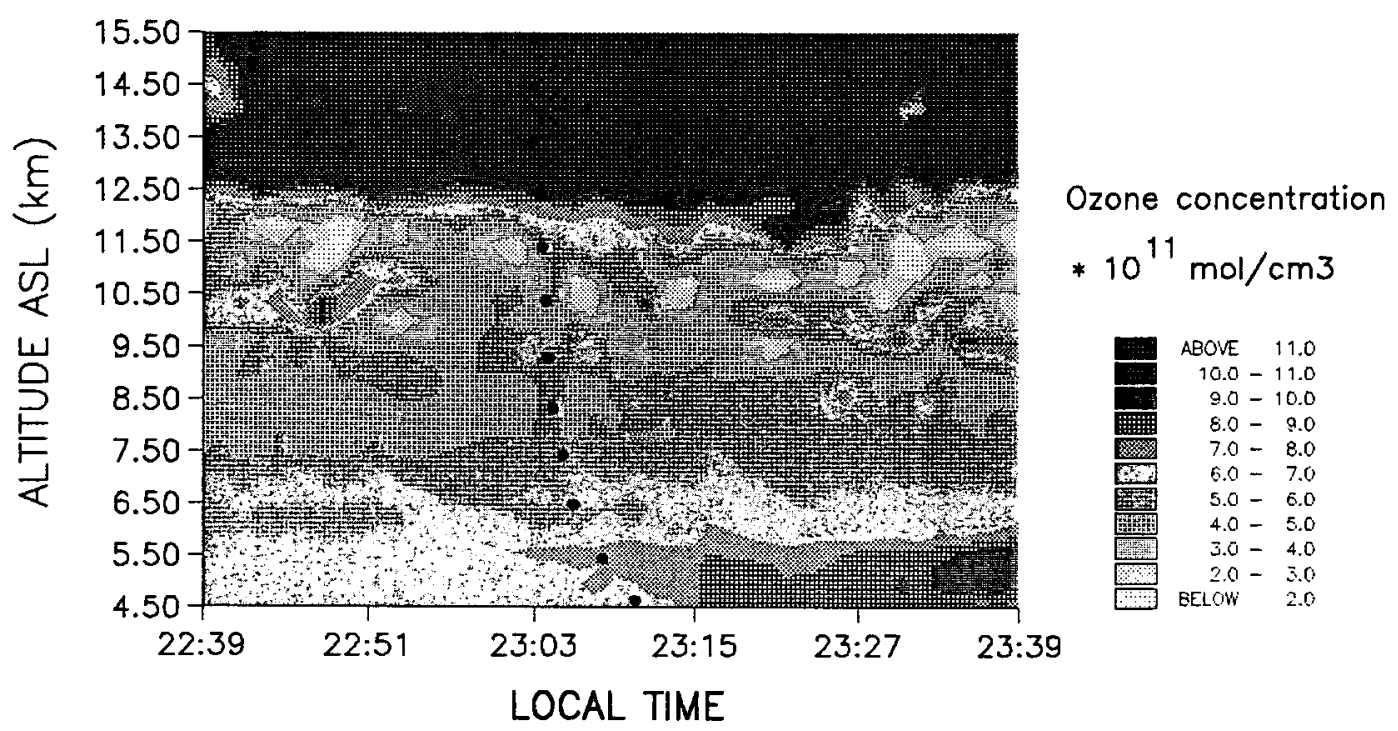

Fig. 6. Ozone evolution between $4.5 \mathrm{~km}$ ASL and $9.5 \mathrm{~km}$ ASL from 2239 to 2339 (local time) as observed by lidar at the OHP. Estimated balloon trajectory is also indicated (black dots). 


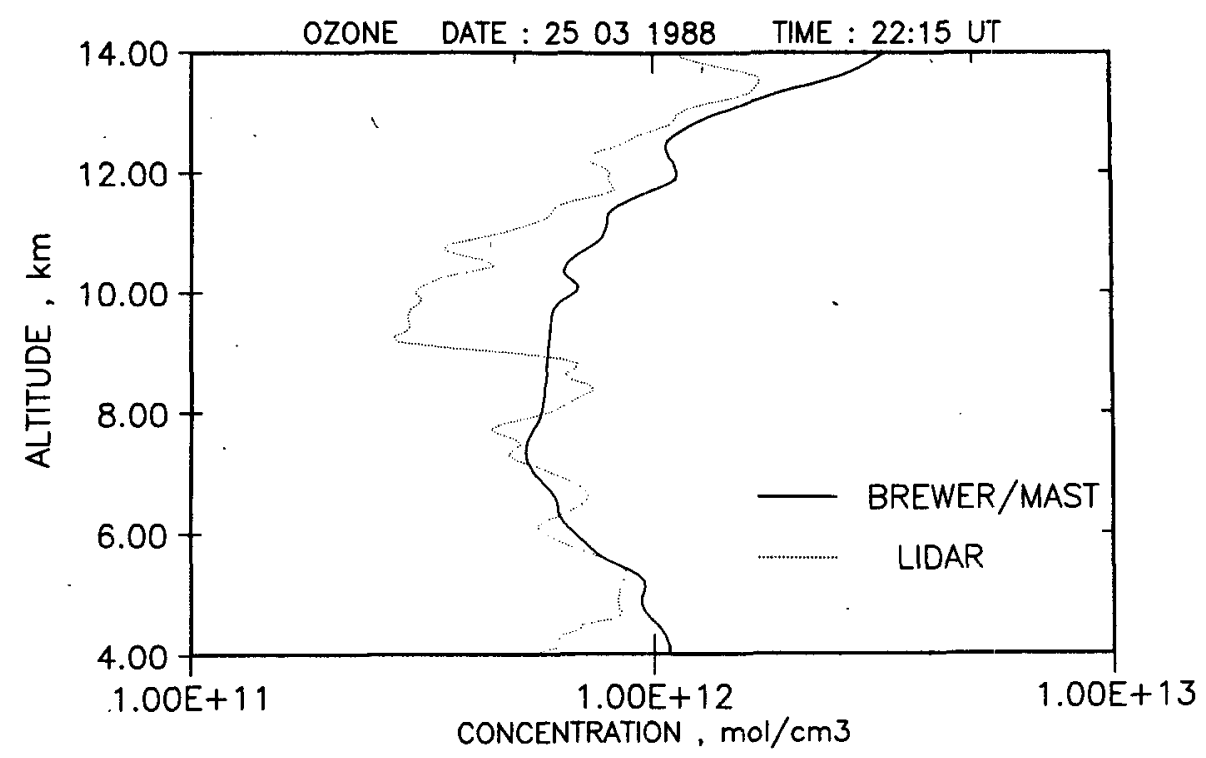

FiG. 7. Comparison of the ozone vertical distribution as measured by lidar and by a Brewer-Mast sonde.

servatoire at that time. The lidar profiles taken about 2303 are therefore adequate for the comparison of lidar and Brewer-Mast data.

\section{Future developments}

The grating spectrometer has been used in the lidar setup instead of the UV broadband filter. An example of a nighttime ozone profile is presented in Fig. 8 as a result of an averaging of 10000 shots for each simultaneously recorded wavelength ( $289 \mathrm{~nm}, 299 \mathrm{~nm}$ ). The performances of the system, including the grating spectrometer, are somewhat similar to the measurements discussed in section 4 . The statistical error is increased by about 1.3 since the lidar optical efficiency

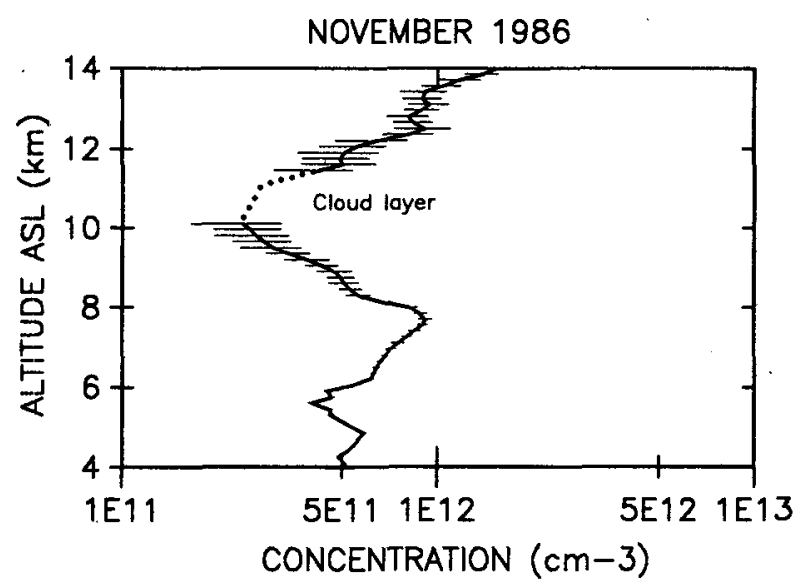

FIG. 8. Ozone concentration vertical profile measured at night by lidar at the OHP (grating spectrometer). is reduced by a factor of 1.7. This reduction in the optical efficiency includes both the lower transmission of the grating spectrometer and the fact that absorbing dispersive elements are no longer needed to separate the transmitted beams $(289 \mathrm{~nm}, 299 \mathrm{~nm})$ from the residual radiation not converted in the Raman cell ( 266 $\mathrm{nm}$ ). In its final version the lidar will record simultaneously more than two wavelengths (the $266 \mathrm{~nm}$ signal, but also the $532 / 355 \mathrm{~nm}$ signal resulting from further doubling/tripling of the residual Nd:YAG infrared output not converted in the second and fourth harmonic generators). This is mandatory for ozone measurements in the PBL where additional information is necessary to correct the aerosol interferences in regions where the aerosol backscatter coefficient is rapidly variable with altitude. We have seen throughout the data presented in section 4 that cloud interferences at the tropopause level are often a severe limitation. Measurement of the cloud differential absorption using the additional wavelength should also be possible (Browell et al. 1985).

The grating spectrometer has a bandwidth smaller than $3 \mathrm{~nm}$ making thus possible daytime measurements. For such a bandwidth, we calculated a background skylight level of $5 \times 10^{9}$ photoelectrons per second at $299 \mathrm{~nm}$ for the lidar parameters used in section 3 . This value compares reasonably well with experimental data obtained with our system for a sun zenith angle of 30 degrees and a zenith pointing lidar. The statistical error on daytime ozone concentrations at $10 \mathrm{~km}$ does not exceed $10 \%$, thus extending our measurement capabilities toward a full diurnal survey of the ozone concentrations in the troposphere up to $10 \mathrm{~km}$. 


\section{Conclusion}

A new lidar system using a Nd:YAG and Raman shifting techniques is under development for ground based and airborne investigation of tropospheric ozone with high vertical $(0.3-1 \mathrm{~km})$ and temporal ( $<2 \mathrm{~min})$ resolutions. The new lidar has been used at the Observatoire de Haute Provence for free tropospheric ozone measurements and the results are satisfactory, with a $10 \%$ variance on the ozone concentration up to $14 \mathrm{~km}$ and a $1 \%$ bias on the mean value. A good agreement with Brewer-Mast ozonesonde data was found considering the limits of the ozonesonde measurements in the lower part of the troposphere, which are often degraded by contamination of the sonde intake system. This latter comparison has been discussed thoroughly in this paper, with an emphasis on the usefulness of the bidimensional representation constructed from lidar data. The final version of the lidar including the grating spectrometer has been tested for nighttime measurements in the free troposphere and the results are similar to those obtained using a UV broad band filter. As discussed in section 5, the future developments will make possible the analysis of more than two wavelengths and daytime operation.

Acknowledgments. This work has been supported by the French Ministère de la Recherche and Ministère de l'Environnement. Alexandros Papayannis held a Doctoral Fellowship from the State Scholarship Foundation of Greece (IKY) for the duration of this research program.

\section{REFERENCES}

Browell, E. V., S. Ismail and S. Shipley, 1985: Ultraviolet DIAL measurements of $\mathrm{O}_{3}$ profiles in regions of spatially inhomogeneous aerosols. Appl. Opt., 24, 2827-2836.
,E. F. Danielsen, S. Ismail, G. L. Gregory and S. M. Beck, 1987: Tropopause fold structure determined from airborne lidar and in situ measurements. J. Geophys. Res., 92, 2112-2120.

Crutzen, P. J., 1988: Tropospheric ozone: an overview. Tropospheric Ozone, I. S. A. Isaksen, Ed., D. Reidel, 3-32.

De Muer, D., and H. Malcorps, 1984: The frequency response of an electrochemical ozone sonde and its application to the deconvolution of ozone profiles. J. Geophys. Res., 89, 1361-1372.

Fishman, J., 1985: Ozone in the troposphere. Ozone in the Free Atmosphere, R. C. Whitten and S. S. Prasad, Eds., Van Nostrand Reinhold, 161-194.

Frederick, J. E., 1983: Measurement requirements for the detection of ozone trends. Proc. Ozone Correlative Measurements Workshop, NASA Publ. 2362, B1-B19.

Godin, S., 1987: Etude expérimentale par télédétection laser et modélisation de la distribution verticale d'ozone dans la haute stratosphère (Laser remote sensing and modelization of the ozone vertical distribution in the upper stratosphere). $\mathrm{Ph}$.D thesis, Université Paris 6, France.

Logan, J., 1985: Tropospheric ozone: seasonal behavior, trends and anthropogenic influence. J. Geophys. Res., 90, $10463-10482$.

Mégie, G., G. Ancellet and J. Pelon, 1985: Lidar measurements of ozone vertical profiles. Appl. Opt., 24, 3454-3463.

Pelon, J., and G. Mégie, 1982a: Ozone vertical distribution and total content as monitored using a ground based active remote sensing system. Nature, 299, 137-138.

- , and - 1982b: Ozone monitoring in the troposphere and the lower stratosphere: evaluation and operation of a groundbased lidar station. J. Geophys. Res., 87(C7), 4947-4955.

Prinn, R. G., 1988: Toward an improved global network for determination of tropospheric ozone climatology and trends. J. Atmos. Chem., 6, 281-298.

Schotland, R. M., 1964: The determination of the vertical profile of atmospheric gases by means of a ground-based optical radar. Proc. Third Symp. on Remote Sensing of Environment, University of Michigan, Ann Arbor, 215-224.

Theopold, F. A., and J. Rosenberg, 1988: Evaluation of DIAL measurements in presence of signal noise. Proc. 14th International Laser Radar Conf., San Candido, Italy, 209-211.

Uchino, O. M., Totunaga, M. Maeda and Y. Miyazoe, 1983: Differential-Absorption-Lidar measurement of tropospheric ozone with excimer Raman hydrid laser. Opt. Lett., 8, 347-349.

U.S. Standard Atmosphere, 1976: NOAA, NASA, USAF, U.S. Govt. Printing Office, Washington, DC, 227 pp.

Vernin J., and J. Pelon, 1986: Scidar/lidar description of a gravity wave and associated turbulence: preliminary results. Appl. Opt., $25,2874-2877$. 